Jurnal Indonesia Sosial Teknologi: p-ISSN: 2723 - 6609

e-ISSN : 2745-5254

Vol. 2, No. 3 Maret 2021

\title{
FAKTOR DOMINAN YANG BERPENGARUH PADA PENINGKATAN BIAYA PEMELIHARAAN JALAN DI KOTA CIREBON
}

\section{Edi Mulyana}

Sekolah Tinggi Teknologi Cirebon, Indonesia

Email: e.mulyana@ymail.com

\section{Abstract}

Recently, there are many asphalt pavement early damages found in Cirebon area, either in the form of small crack, reveling, or pavement peeling which contribute to theincrease of road maintenance cost from year to year. The increase of road maintenance cost is caused by several factors in the planning, the execution, as well as in the maintenance process. This study aims to explore the dominant factors affecting the increase of road maintenance cost in Cirebon. The research findings are expected to provide positive feedback to related institutions. This study uses survey method, by distributing of questionnaire to respondents which consist of contractors, consultants, taskmasters, and experts. Questionnaire data are processed using SPSS 19 statistical analysis, with risk factors which affect the increase of the road maintenance cost as independent variable $(X)$ and maintenance cost as dependent variable (Y). The research concludes that there are six most dominant factors affecting rise of road maintenance cost in Cirebon, which are 1) the underpriced bid (77.62\%), 2) the lack of project supervision (74.62\%), 3) the cost estimation error $(70.39 \%)$, 4) the error in the shipping of ordered materials, 5) the poor performance of subcontractors (67.57\%), and 6) natural disaster (62.88\%).

Keyword: dominant factors; effect; maintenance cost.

\section{Abstrak}

Akhir-akhir ini banyak ditemui kerusakan dini perkerasan jalan di Kota Cirebon baik berupa retak kecil (crack), pelepasan butiran (raveling) maupun pengelupasan lapisan perkerasan yang mengakibatkan terus meningkatnya biaya pemeliharaan jalan dalam setiap tahunnya yang disebabkan oleh banyaknya faktor yang mempengaruhi sejak perencaanaan, pelaksanaan hingga pemeliharaan proyekproyek jalan tersebut. Penelitian ini bertujuan untuk mencari faktor-faktor dominan apa yang berpengaruh pada peningkatan biaya pemeliharaan jalan di Kota Cirebon, sehingga hasil penelitian diharapkan dapat memberikan masukan positif kepada instansi terkait. Penelitian menggunakan metode survey, melalui penyebaran kuesioner kepada responden yang terdiri dari kontraktor, konsultan, pemberi tugas dan pakar dibidangnya yang kemudian data kuesionernya diolah dengan analisa statistik SPSS 19 untuk menghasilkan tingkat hubungan antara variabel bebas (X) berupa faktor resiko yang berpengaruh pada peningkatan biaya pemeliharaan dan 
variabel (Y) berupa biaya pemeliharaan. Dari hasil penelitian menyimpulkan bahwa ada 6 (enam) faktor yang paling dominan mempengaruhi peningkatan biaya pemeliharaan yaitu penawaran harga terlalu rendah (77.69), lemahnya pengendalian proyek (74.35), kesalahan estimasi biaya (70.39), material yang dikirim tidak sesuai permintaan (68.35), sub kontraktor tidak bekerja optimal (67.57) dan terjadinya bencana alam (62.88) terhadap biaya pemeliharaan.

Kata kunci: faktor dominan; tingkat pengendali; pemeliharaan jalan.

\section{Pendahuluan}

Pembangunan dan pengembangan infrastruktur masih terus dilakukan, khususnya pada aspek pengembangan jalan, hal ini menjadi faktor penting karena jalan merupakan salah satu aspek penentu kelancaran dalam proses pembangunan perekonomian di Indonesia. Sebagaimana Sahid dkk menjelaskan pembuatan jalan merupakan aspek penting dalam meningkatkan perekonomian bangsa (Sahid, Setianingsih, Solikhin, Mulyono, \& Rahman, 2019). Namun Akhir-akhir ini banyak ditemukan terjadinya kerusakan dini pada proyek-proyek peningkatan jalan di Kota Cirebon. Hal tersebut diindikasikan dengan banyaknya jalan yang baru selesai dikerjakan dan masih masa pemeliharaan maupun setelah pekerjaan diserahterimakan, meskipun umur rencana belum terlampaui, kerusakan-kerusakan kecil berupa retak (crack), pelepasan butiran (raveling) maupun pengelupasan lapisan perkerasan telah terjadi dimana-mana (Laksono, 2010).

Menurut informasi dari Dinas PUPESDM Kota Cirebon tahun 2013 kerusakan tersebut telah menimbulkan adanya peningkatan biaya pemeliharaan jalan pada setiap tahunnya dari rata-rata $5 \%$ menjadi rata-rata $10 \%$ dari ruas jalan yang ada. Peningkatan biaya pemeliharaan jalan yang berlapis dalam tiap tahunnya, menunjukkan terjadinya pemborosan, sehingga keterbatasan anggaran hanya cukup untuk memelihara jalan yang ada, bahkan itupun tidak bisa tuntas secara keseluruhan (Nariyah, 2017).

Berbagai upaya telah dilakukan pemerintah untuk mendorong terjadinya penghematan melalui berbagai regulasi yang memuat nilai-nilai kekinian yang menjadi syarat mutlak pelaksanaan good governance, seperti efisiensi dan efektif (best value for money) terbuka dan bersaing (open competitive), transparan, adil/non-diskriminatif dan akuntabel (Karianga, 2017). Tetapi didalam pelaksanaan pemanfaatan anggaran banyak faktor yang dapat mempengaruhi pelaksanaan proyek-proyek jalan sehingga jalan lebih cepat rusak dan secara otomatis peningkatan biaya pemeliharaan tidak bisa terelakkan lagi seperti terlihat pada tabel 1 berikut: 
Edi Mulyana

Tabel 1. Data Penggunaan Anggaran untuk Biaya Pemeliharaan Jalan di Kota Cirebon Dalam 7 Tahun Terakhir

\begin{tabular}{|c|c|r|r|c|}
\hline No. & Tahun & $\begin{array}{c}\text { Luas } \\
\text { Kerusakan } \\
(\mathrm{m} 2)\end{array}$ & $\begin{array}{c}\text { Biaya } \\
\text { per m2/tahun } \\
(\mathrm{Rp})\end{array}$ & \multicolumn{1}{c|}{ Total Biaya } \\
\hline & 2006 & 2.884 & 702.367 & 2.025 .626 .428 \\
\hline 1 & 2007 & 3.585 & 737.269 & 2.643 .109 .365 \\
\hline 3 & 2008 & 8.353 & 709.760 & 5.928 .625 .280 \\
\hline 4 & 2009 & 11.872 & 836.306 & 9.928 .624 .832 \\
\hline 5 & 2010 & 9.773 & 1.089 .913 & 10.651 .719 .749 \\
\hline 6 & 2011 & 5.899 & 1.221 .688 & 7.206 .737 .512 \\
\hline 7 & 2012 & 10.290 & 1.343 .856 & 13.828 .278 .240 \\
\hline
\end{tabular}

Sumber : DPUPESDM Kota Cirebon Tahun 2013

Pelaksanaan kegiatan pemeliharaan jalan berdasarkan anggaran yang tersedia, mengingat sulitnya menyediakan anggaran untuk memenuhi semua kebutuhan perbaikan jalan yang ada, disisi lain kerusakan jalan berdampak banyak kepada kehidupan sosial masyarakat.

Permasalahan kerusakan lebih awal pada proyek-proyek pembangunan/ peningkatan jalan di Kota Cirebon tersebut melatarbelakangi perlunya mengetahui faktor-faktor apa apa saja yang mempengaruhinya, sehingga diharapkan dapat ditemukannya faktor dominan yang berpengaruh pada peningkatan biaya pemeliharaan pada setiap tahunnya

Tujuan dari penelitian ini adalah untuk mendapatkan faktor dominan yang mempengaruhi peningkatan biaya pemeliharaan jalan di Kota Cirebon. Kegunaan penelitian yang diharapkan adalah sebagai bahan evaluasi terhadap berbagai masalah yang sering muncul di dalam pelaksanaan proyek-proyek peningkatan jalan di Kota Cirebon serta dapat memberikan masukan kepada pihak-pihak terkait agar pelaksanaan proyek-proyek jalan dapat dilaksanakan dengan mutu yang baik, tepat waktu dan biaya yang efisien, sehingga tingkat kerusakan bisa ditekan sekecil mungkin dan biaya pemeliharaan masih dalam batas kewajaran. Hasil dari penelitian ini diharpakan dapat menjadi masukan bagi pemerintah daerah khususnya kota Cirebon dalam menetapka anggaran pembiayaan infrastruktur jalan.

\section{Metode Penelitian}

Secara prinsip metodologi dalam penelitian ini dapat dilihat pada gambar dibawah ini: 


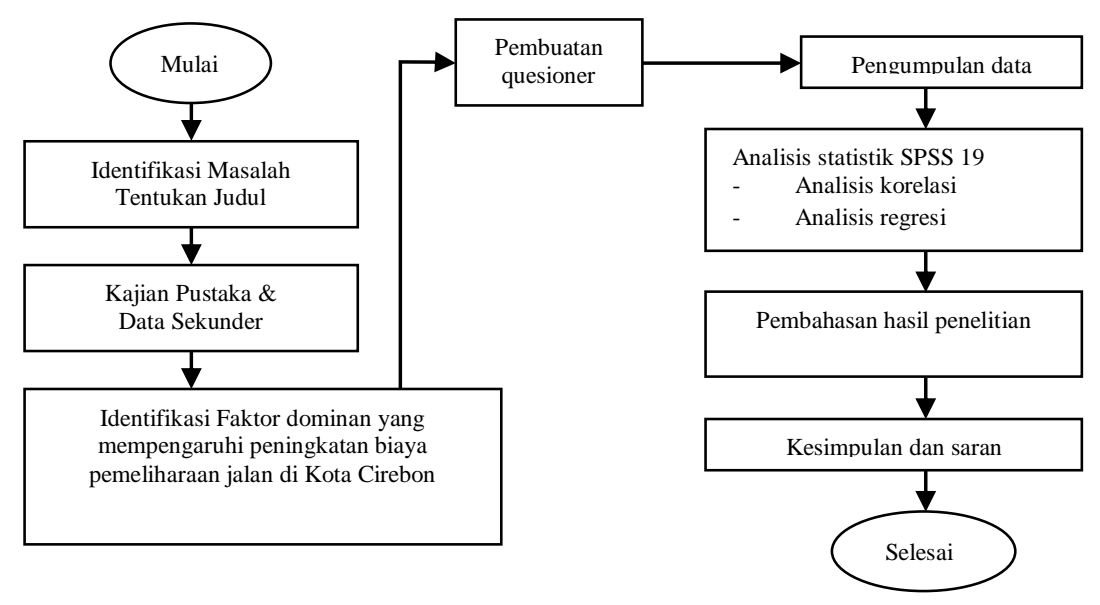

Gambar 1. Alur Metodologi Penelitian

Tahapan kegiatannya secara garis besar adalah sebagai berikut:

1. Dimulai dengan identifikasi masalah bersamaan dengan penentuan judul didukung oleh kajian pustaka, baik data primer maupun sekunder.

2. Tahap penyusunan identifikasi faktor resiko yang mempengaruhi peningkatan biaya pemeliharaan sebagai descripsi operasional variabel penelitian yang terdiri dari 43 variabel.

3. Tahap pembuatan kuesioner dengan masing-masing item pernyataan terdiri dari 5 skala pengukuran, dilanjutkan dengan pengumpulan data dari para kontraktor, konsultan, pemberi tugas dan pakar dibidangnya di Kota Cirebon.

4. Tabulasi data kemudian di analisa dengan analisa statistik SPSS 19 baik analisa korelasi maupun regresi.

5. Pembahasan hasil analisa statistic untuk memperoleh jawaban atas pertanyaan penelitian berdasarkan hasil analisa data yang dilakukan.

6. Tahap kesimpulan dan saran

\section{Hasil dan Pembahasan}

\section{A. Hasil Penelitian}

hasil pengujian validitas terhadap output korelasi dan analisa regresi, dari 43 variabel terdapat 6 variabel yang memiliki angka korelasi yang sangat kuat seperti tabel dibawah ini;

Tabel 1. Correlation

\begin{tabular}{|c|c|c|c|c|c|c|c|c|}
\hline & & $\mathrm{X} 10$ & $\mathrm{X} 23$ & $\mathrm{X} 24$ & $\mathrm{X} 25$ & $\mathrm{X} 35$ & X9 & $\mathrm{y}$ \\
\hline \multirow{3}{*}{ X10 } & \multirow{3}{*}{$\begin{array}{l}\text { Pearson correlation } \\
\text { sig. (2-tailed) } \\
\mathrm{N}\end{array}$} & 1 & $.707 * *$ & $.643 * *$ & $.739 * *$ & $.672 * *$ & $.588 * *$ & $.827 * *$ \\
\hline & & & .000 & .000 & .000 & .000 & .000 & .000 \\
\hline & & 40 & 40 & 40 & 40 & 40 & 40 & 40 \\
\hline \multirow{3}{*}{ X23 } & \multirow{3}{*}{$\begin{array}{l}\text { Pearson Correlation } \\
\text { sig. (2-tailed) } \\
\mathrm{N}\end{array}$} & $.707 * *$ & 1 & $.739 * *$ & $.741 * *$ & $.741 * *$ & $.565 * *$ & $.839 * *$ \\
\hline & & .000 & & .000 & .000 & .000 & .000 & .000 \\
\hline & & 40 & 40 & 40 & 40 & 40 & 40 & 40 \\
\hline \multirow{3}{*}{ X24 } & \multirow{3}{*}{$\begin{array}{l}\text { Pearson Correlation } \\
\text { sig. (2-tailed) } \\
\mathrm{N}\end{array}$} & $.643 * *$ & $.739 * *$ & 1 & $.683 * *$ & $.774 * *$ & $.590 * *$ & $.822 *$ \\
\hline & & .000 & .000 & & .000 & .000 & .000 & .000 \\
\hline & & 40 & 40 & 40 & 40 & 40 & 40 & 40 \\
\hline
\end{tabular}




\begin{tabular}{|c|c|c|c|c|c|c|c|c|}
\hline \multirow{3}{*}{$\mathrm{X} 25$} & pearson correlation & $.739 * *$ & $.741 * *$ & $.683 * *$ & 1 & $.711 * *$ & $.739 * *$ & $.864 * *$ \\
\hline & sig. (2-tailed) & .000 & .000 & .000 & & .000 & .000 & .000 \\
\hline & $\mathrm{N}$ & 40 & 40 & 40 & 40 & 40 & 40 & 40 \\
\hline \multirow{3}{*}{$\mathrm{X} 35$} & \multirow{3}{*}{$\begin{array}{l}\text { Pearson Correlation } \\
\text { sig. (2-tailed) } \\
\mathrm{N}\end{array}$} & $.672 * *$ & $.741 * *$ & $.774 * *$ & $.711 * *$ & 1 & $.746^{* *}$ & $.881 * *$ \\
\hline & & .000 & .000 & .000 & .000 & & .000 & .000 \\
\hline & & 40 & 40 & 40 & 40 & 40 & 40 & 40 \\
\hline \multirow{3}{*}{ X9 } & \multirow{3}{*}{$\begin{array}{l}\text { Pearson Correlation } \\
\text { sig. (2-tailed) } \\
\mathrm{N}\end{array}$} & $.588 * *$ & $.565 * *$ & $.590 * *$ & $.733 * *$ & $.746 * *$ & 1 & $.739 * *$ \\
\hline & & .000 & .000 & .000 & .000 & .000 & & .000 \\
\hline & & 40 & 40 & 40 & 40 & 40 & 40 & 40 \\
\hline \multirow{3}{*}{$\mathrm{y}$} & \multirow{3}{*}{$\begin{array}{l}\text { Pearson Correlation } \\
\text { sig. (2-tailed) } \\
\mathrm{N}\end{array}$} & $.827 * *$ & $.839 * *$ & $.822 * *$ & $.864 * *$ & $.881 * *$ & $.793 * *$ & 1 \\
\hline & & .000 & .000 & .000 & .000 & .000 & .000 & \\
\hline & & 40 & 40 & 40 & 40 & 40 & 40 & 40 \\
\hline
\end{tabular}

Ket: **correlation is significant at the 0,01 level (2-tailed)

Sumber: data diolah (2014)

Berdasarkan tabel 1 di atas, terlihat bahwa hubungan antara variabel-variabel yang mempengaruhi peningkatan biaya pemeliharaan jalan dengan biaya pemeliharaan jalan di kota Cirebon secara secara keseluruhan signifikan. Artinya, adanya hubungan yang signifikan antara variabel-variabel yang mempengaruhi peningkatan biaya pemeliharaan jalan dengan biaya pemeliharaan jalan di kota Cirebon secara simultan.

1) Berdasarkan perhitungan diperoleh angka korelasi antara material yang dikirim tidak sesuai dengan permintaan dengan biaya pemeliharaan jalan sebesar 0.827 , termasuk korelasi sangat kuat. Nilai koefisien determinasi $\mathrm{r}^{2}=0.827^{2} \times 100 \%=$ $68.39 \%$, artinya besarnya sumbangan variabel material yang dikirim tidak sesuai dengan permintaan terhadap biaya pemeliharaan jalan sebesar $68.39 \%$ dan sisanya $31.61 \%$ ditentukan oleh variabel lainnya

2) Berdasarkan perhitungan diperoleh angka korelasi antara kesalahan dalam estimasi biaya dengan biaya pemeliharaan jalan sebesar 0.839 , termasuk korelasi sangat kuat. Nilai koefisien determinasi $\mathrm{r}^{2}=0.839^{2} \times 100 \%=70.39 \%$ artinya besarnya sumbangan variabel kesalahan dalam estimasi biaya terhadap biaya pemeliharaan jalan sebesar $70.39 \%$ dan sisanya $29.61 \%$ ditentukan oleh variabel lainnya

3) Berdasarkan perhitungan diperoleh angka korelasi antara sub kontraktor tidak bekerja optimal dengan biaya pemeliharaan jalan sebesar 0.822 , termasuk korelasi sangat kuat. Nilai koefisien determinasi $\mathrm{r}^{2}=0.822^{2}$ x $100 \%=67.57 \%$ artinya besarnya sumbangan variabel sub kontraktor tidak bekerja optimal terhadap biaya pemeliharaan sebesar $67.57 \%$ dan sisanya $32.43 \%$ ditentukan oleh variabel lainnya

4) Berdasarkan perhitungan diperoleh angka korelasi antara lemahnya pengendalian proyek dengan biaya pemeliharaan jalan sebesar 0.864, termasuk korelasi sangat kuat. Nilai koefisien determinasi $\mathrm{r}^{2}=0.864^{2} \times 100 \%=74.62 \%$ artinya besarnya sumbangan variabel lemahnya pengendalian proyek terhadap biaya pemeliharaan sebesar $74.62 \%$ dan sisanya $25.38 \%$ ditentukan oleh variabel lainnya

5) Berdasarkan perhitungan diperoleh angka korelasi antara penawaran terlalu rendah dengan biaya pemeliharaan jalan sebesar 0.881, termasuk korelasi sangat kuat. Nilai koefisien determinasi $\mathrm{r}^{2}=0.881^{2}$ x $100 \%=77,62 \%$ artinya besarnya 
sumbangan variabel penawaran terlalu rendah terhadap biaya pemeliharaan sebesar $77,62 \%$ dan sisanya $22.38 \%$ ditentukan oleh variabel lainnya

6) Berdasarkan perhitungan diperoleh angka korelasi antara adanya bencana alam dengan biaya pemeliharaan jalan sebesar 0.793 , termasuk korelasi sangat kuat. Nilai koefisien determinasi $\mathrm{r}^{2}=0.793^{2}$ x $100 \%=62.88 \%$ artinya besarnya sumbangan variabel adanya bencana alam terhadap biaya pemeliharaan sebesar $62.88 \%$ dan sisanya $37.12 \%$ ditentukan oleh variabel lainnya.

\section{B. Pembahasan}

Penelitian tentang identifikasi faktor dominan yang berpengaruh pada peningkatan biaya pemeliharaan jalan di Kota Cirebon, setelah dilakukan dengan metode statistik melalui analisis korelasi maupun analisis regresi linier berganda dengan menggunakan SPSS 19 sebagai software pengolah data diperoleh suatu model persamaan regresi linier berganda yaitu :

$\mathrm{Y}=0,193 \mathrm{X}_{10}+0,134 \mathrm{X}_{23}+0,126 \mathrm{X}_{24}+0,154 \mathrm{X}_{25}+0,225 \mathrm{X}_{35}+0,160 \mathrm{X}_{39}$

Dari model tersebut diatas dengan menggunakan "one tailed" (pengujian satu sisi), maka dapat dijelaskan bahwa terdapat 6 (enam) variabel $\mathrm{X}$ yang dapat mempengaruhi nilai Y.

Model persamaan regresi linier berganda tersebut menunjukkan bahwa setiap ada kenaikan variabel $\mathrm{X}_{10}$ sebesar satu satuan, maka terdapat penurunan variabel $\mathrm{Y}$ sebesar 0,193, dan setiap ada kenaikan variabel $X_{23}$ sebesar satu satuan maka terdapat penurunan variabel $\mathrm{Y}$ sebesar 0,134 , dan setiap ada kenaikan variabel $\mathrm{X}_{24}$

sebesar satu satuan maka terdapat penurunan variabel Y sebesar 0,126, dan setiap ada kenaikan variabel $\mathrm{X}_{25}$ sebesar satu satuan maka terdapat penurunan variabel $\mathrm{Y}$ sebesar 0,154, dan setiap ada kenaikan variabel $X_{35}$ sebesar satu satuan maka terdapat penurunan variabel $\mathrm{Y}$ sebesar 0,225 , dan setiap ada kenaikan variabel $\mathrm{X}_{39}$ sebesar satu satuan maka terdapat penurunan variabel Y sebesar 0,160 .

Pada perhitungan sebelumnya diperoleh nilai $\mathrm{R}^{2}=0,946$, hal ini menunjukkan bahwa 94,6\% dari simpangan nilai $Y$ tersebut dapat diterangkan oleh variabel $X$, dan 5,4\% lagi penyimpangan yang ada dalam $\mathrm{Y}$ yang tidak dapat diterangkan oleh variabel $\mathrm{X}$.

Dari perhitungan dapat dijelaskan pula bahwa masing-masing variabel memberikan retribusi untuk $\mathrm{Y}$, yaitu variabel $\mathrm{X}_{35}$ memberikan kontribusi paling dominan sebesar $77,62 \%$, dilanjutkan variabel $X_{25}$ sebesar $74,62 \%$, variabel $X_{23}$ sebesar $70,39 \%$, variabel $X_{10}$ sebesar $68,39 \%$, variabel $X_{24}$ sebesar $67,57 \%$, dan variabel $X_{39}$ sebesar $62,88 \%$,

Dari analisis statistik terhadap penelitian yang telah dilakukan menghasilkan 6 (enam) variabel yang paling dominan berpengaruh kepada peningkatan biaya pemeliharaan jalan di Kota Cirebon.

Dari ke 6 (enam) variabel tersebut kondisinya dapat diuraikan sebagai berikut :

1. Penawaran harga terlalu rendah

Variabel penawaran harga terlalu rendah merupakan indikator dari faktor lemahnya pengikatan Surat Perjanjian Pekerjaan (kontrak). Harga penawaran berhubungan langsung dengan biaya pelaksanaan proyek. Harga penawaran yang menjadi pengikatan didalam kontrak biasanya bukan harga utuh untuk 
diimplementasikan pada kegiatan fisiknya saja, didalamnya terkandung biaya proses lelang, administrasi proyek, biaya koordinasi dan biaya non teknis lainnya yang tidak muncul didalam item-item pekerjaan yang ditawarkan.

Akhir-akhir ini proses pelelangan pekerjaan konstruksi pemerintah dituntut adanya efisiensi, sehingga terjadi penawaran harga dari pihak kontraktor jauh lebih rendah dari pagu yang direncanakan. Bagi kontraktor harga penawaran rendah semata-mata untuk mendapatkan pekerjaan, padahal resiko non teknis yang timbul akibat perolehan pekerjaan tidak pernah ada dalam analisa biaya yang menjadi dasar munculnya harga satuan pekerjaan.

Harga penawaran yang rendah ditambah resiko non teknis menjadi beban yang berat terhadap biaya pelaksanaan pekerjaan. Sehingga potensi sumber daya yang dipersyaratkan didalam dokumen kontrak tidak dapat diimplementasikan dengan tepat. Akibatnya terjadi kerusakan pekerjaan lebih awal dari yang direncanakan, yang berpotensi sangat besar pada meningkatnya biaya pemeliharaan.

2. Lemahnya pengendalian proyek

Variabel lemahnya pengendalian proyek merupakan indikator dari lemahnya faktor manajemen pelaksanaan kontraktor.

Sasaran dari pengendalian proyek adalah untuk menghasilkan produk agar sesuai dengan batasan anggaran, jadwal dan mutu yang telah ditentukan. Lemahnya pengendalian proyek selama ini karena tidak dilaksanakannya cara pengendalian yang sistematis dan bertanggung jawab. Masing-masing unsur yang terlibat pada pengendalian tidak bekerja sesuai tugas dan fungsinya dengan baik dan beban psykologis akibat kebijakan birokrasi memiliki andil besar melemahnya sistem pengendalian. Sehingga kelemahan sumber daya yang mendukung pelaksanaan proyek dibiarkan, bahkan ada kalanya secara bersama-sama bersepakat melakukan penyimpangan terhadap pekerjaan yang sedang dilaksanakan. Kondisi ini semakin memperparah hasil akhir kualitas pekerjaan.

3. Kesalahan dalam estimasi biaya

Variabel kesalahan dalam estimasi biaya merupakan indikator dari lemahnya faktor manajemen pelaksanaan kontraktor. Estimasi biaya untuk pelaksanaan yang terjadi dengan cara memperhitungkan terlebih dahulu biaya-biaya non teknis yang menjadi beban kontraktor. Setelah itu baru menghitung rencana biaya pelaksanaan ditambah keuntungan.

Kesalahan yang dilakukan oleh kontraktor dalam membuat estimasi biaya karena kurang memperhatikan standar mutu pekerjaan, tapi lebih mengutamakan rugi/laba untuk kelangsungan usaha pada jangka waktu tertentu.. Estimasi biaya tanpa mengutamakan kaidah-kaidah keteknikan menjadi persoalan timbulnya penyimpangan pekerjaan. Hal ini mengakibatkan hasil pekerjaan menjadi cepat rusak.

4. Material yang dikirim tidak sesuai permintaan

Variabel material yang dikirim tidak sesuai permintaan merupakan indikator dari lemahnya faktor sumber daya material. Material yang datang sebagian besar 
sudah berupa aspal panas yang sudah tercampur (hotmix), tanpa diuji dulu komposisi campurannya ditambah jumlah yang dikirim tidak sesuai kebutuhan dilapangan, sehingga bukan saja komposisi campuran yang tidak tepat, juga ketebalan lapisan menjadi berkurang. Ketebalan lapisan hotmix yang seharusnya rata-rata $5 \mathrm{~cm}$, menjadi rata-rata $2,5 \mathrm{~s} / \mathrm{d} 3,5 \mathrm{~cm}$. Semakin komposisi material campuran aspal hotmix tidak sesuai rencana lapisan aspal semakin mudah retak, butiran mudah lepas hingga pengelupasan lapisan perkerasan, akibatnya jalan berlubang dimana-mana memerlukan.

5. Sub kontraktor tidak bekerja optimal

Variabel sub kontraktor tidak bekerja optimal merupakan indikator dari lemahnya faktor manajemen pelaksanaan kontraktor. Sebagian besar setelah kontraktor memperoleh kontrak pekerjaan, selanjutnya sebagian atau seluruh pekerjaan diberikan kepada sub kontraktor dengan harga yang berbeda-beda untuk setiap jenis pekerjaan. Berdasarkan hasil wawancara dengan beberapa kontraktor diperoleh informasi sebagai berikut :

1) Untuk pekerjaan irigasi/drainase dengan konstruksi pasangan batu kali harga sub kontraktor antara 50\% s.d 55\% dari harga kontrak.

2) Untuk pekerjaan gedung perkantoran dan sekolah ada pada kisaran angka antara $65 \%$ s.d $70 \%$

3) Untuk pekerjaan jalan konstruksi penetrasi ada pada kisaran angka antara $60 \%$ s.d $65 \%$, sedangkan untuk pekerjaan jalan hotmix ada pada kisaran angka antara $65 \%$ s.d $70 \%$ dari harga kontrak.

4) Sedangkan pekerjaan yang sebagian di sub-kontraktorkan, biasanya berhubungan dengan pengadaan tenaga kerja, material atau sewa peralatannya saja.

5) Bilamana sub kontraktor mengambil seluruh pekerjaan, dengan harga pekerjaan yang diterima seperti diatas maka sub kontraktor paling tidak akan melaksankan 10\% dibawah angka-angka yang disepakati antara sub kontraktor dan main kontraktornya.

6) Kondisi ini berakibat tidak optimalnya pekerjaan sub kontraktor bila dihubungkan dengan sasaran yang akan dicapai sesuai rencana kerja yang dipersyaratkan dalam dokumen kesepakatan antara kontraktor dan pemberi tugas. Sehingga sangat wajar bila pekerjaan jalan menjadi capat rusak, biaya pemeliharaan meningkat terus tiap tahunnya.

6. Adanya bencana alam

Variabel adanya bencana alam merupakan indikator dari faktor kondisi eksternal. Seperti diuraikan pada deskripsi lokasi penelitian bab sebelumnya bahwa Cirebon terletak didaerah pantai dan memiliki dataran yang luas.

Karena berada didaerah pantai maka sistem pelepasan air hujan, dipengaruhi oleh pasang surut air laut. Bilamana terjadi hujan dengan intensitas tinggi selama 2 (dua) jam berturut-turut tanpa henti, maka bencana alam berupa banjir akan terjadi 
Edi Mulyana

dimana-mana, tak terkecuali jalan-jalan pun digenangi air dalam kurun waktu tertentu.

Air yang menggenangi jalan akan masuk kepada pori-pori permukaan jalan, menembus struktur jalan hingga jalan menjadi cepat rusak.

Kerusakan jalan akibat banjir tentunya menjadi lebih parah bilamana jalan yang terbangun dengan mutu yang tidak sesuai persyaratan.

Kerusakan tidak hanya lapisan permukaan saja, tetapi struktur jalanpun mengalami penurunan daya dukung, sehingga memerlukan biaya lebih banyak untuk memperbaikinya.

Dari 6 (enam) variabel yang paling dominan, 3 (tiga) variabel merupakan faktor manajemen pelaksanaan kontraktor, 1 (satu) variabel merupakan faktor perjanjian kerja (kontrak), 1 (satu) variabel merupakan faktor sumber daya material dan 1 (satu) variabel merupakan faktor eksternal.

\section{Kesimpulan}

Dari pembahasan diatas, maka secara berurutan faktor dominan yang berpengaruh pada peningkatan biaya pemeliharaan jalan adalah : 1) Penawaran harga terlalu rendah; 2) Lemahnya pengendalian proyek; 3) Kesalahan dalam estimasi biaya; 4) Material yang dikirim tidak sesuai permintaan; 4) Sub kontraktor tidak bekerja optimal; dan 5) Adanya bencana alam.

Berdasarkan hasil analisis pengolahan data dengan metode statistic (analisa, korelasi dan regresi) serta hasil perhitungan, dapat dijelaskan bahwa terdapat korelasi sangat kuat antara penawaran harga terlalu rendah, lemahnya pengendalian proyek, kesalahan dalam estimasi biaya, material yang dikirim tidak sesuai permintaan, sub kontraktor tidak bekerja optimal dan adanya bencana alam terhadap peningkatan biaya pemeliharaan jalan di Kota Cirebon. 
Faktor Dominan yang Berpengaruh pada Peningkatan Biaya Pemeliharaan Jalan di Kota Cirebon

\section{Bibliography}

Anonim. (2007). Peraturan Menteri Pekerjaan Umum No.7 tentang pedoman penilaian penyedia jasa konstruksi.

Anonim. (2007). Peraturan Menteri Pekerjaan Umum No.42 tentang petunjuk teknis penggunaan Dana Alokasi Khusus Bidang Infrastruktur.

Dipohusodo, I. (1996). Manajemen proyek dan konstruksi, Yogyakarta. Penerbit Kanisius

Fahan. (2005), Analisa Efisiensi Penggunaan Alat Berat. UII, Yogyakarta.

Indrawan, Sony. (2011). Estimasi Biaya Pemeliharaan Jalan "Cost Signifikan Model”, Studi Kasus Pemeliharaan Jalan Kabupaten Di Kabupaten Jembrana. Jurnal Teknik Sipil Universitas Udayana Denpasar Bali

Istimawan, Dipohusodo. (1996). Manajemen Proyek Konstruksi Penerbit : Kanisius

Laksono, Anggoro. (2009). Faktor-Faktor Yang Mempengaruhi Kerusakan Jalan. Jurnal Teknik Sipil Universitas Sebelas Maret Surakarta.

Karianga, H. (2017). Carut-Marut Pengelolaan Keuangan Daerah di Era Otonomi Daerah. Prenada Media.

Laksono, A. D. (2010). Model Penerapan Standar Mutu pada Pekerjaan Pemeliharaan Jalan Ditinjau dari Kompetensi SDM Pengelola. Surakarta. Universitas Sebelas Maret Surakarta.

Mulyono, Taufik. (2006). Kinerja Pemberlakuan Standar Mutu Perkerasan Pada Peningkatan Dan Pemeliharaan Jalan Nasional-Propinsi. Jurnal Teknik Sipil Universitas Gajah Mada Yogyakarta.

Mulyono, Taufik. (2007). Persepsi Pakar : Verifikasi Variabel Yang Mempengaruhi Pemberlakuan Standar Mutu Perkerasan Jalan. Jurnal Teknik Sipil Universitas Gajah Mada Yogyakarta.

Malik, Alfian. (2010). Bisnis Jasa Pelaksana Konstruksi. Penerbit : Andi

Nariyah, H. (2017). Peranan Reformasi Birokrasi dan Budaya Organisasi Terhadap Kinerja Organisasi Pada Sekretariat Daerah Kota Cirebon. Jurnal Ilmiah Publika, $5(2)$.

R.J. Mockler. (1972). The Management Control Process. Prentice Hall.

Sahid, M. N., Setianingsih, I., Solikhin, M., Mulyono, G. S., \& Rahman, B. F. N. (2019). Analisis Faktor-Faktor Penting Penyebab Masalah Penambahan Biaya Pada Proyek Jalan Kabupaten Klaten. Media Teknik Sipil, 17(2), 1-8.

Soeharto, Iman. (2001). Manajemen Proyek jilid II (dari Konseptual sampai Operasional). Penerbit : Erlangga 
Edi Mulyana

Stukhart, G. (1995). Construction Materials Management, Newyork, Marcel Dekker, Inc.

Sugiyono. (2001), Perencanaan Kebutuhan Sumber daya (Agregrat Planning Chapter3).

Sugiyono. (2002). Statika Untuk Penelitian. Penerbit : Alpabeta-Bandung.

Thabrani et al. (2013). Faktor-Faktor Penyebab Pengerjaan Ulang (Rework) Yang Berkaitan Dengan Manajerial Pada Proyek Konstruksi Jalan Di Kabupaten Rokan Hulu. Jurnal Teknik Sipil, Universitas Pasir Pengaraian. 